“C 2018 IEEE. Personal use of this material is permitted. Permission from IEEE must be obtained for all other uses, in any current or future media, including reprinting/republishing this material for advertising or promotional purposes, creating new collective works, for resale or redistribution to servers or lists, or reuse of any copyrighted component of this work in other works." 


\section{Sequential Model Predictive Control of Direct Matrix Converter without Weighting Factors}

\author{
Jianwei Zhang, Li Li \\ Faculty of Engineering and IT \\ University of Technology Sydney \\ Sydney, Australia \\ Jianwei.Zhang@uts.edu.au \\ Li.Li@uts.edu.au
}

\author{
Margarita Norambuena, Jose Rodriguez \\ Facultad de Ingeniería \\ Universidad Andrés Bello \\ Santiago, Chile \\ margarita.norambuena@gmail.com \\ jose.rodriguez@unab.cl
}

\author{
David G. Dorrell \\ Howard College Campus \\ University of KwaZulu-Natal \\ Durban, South Africa \\ d.g.dorrell@gmail.com
}

\begin{abstract}
The direct matrix converter (MC) is a promising converter that performs direct AC-to-AC conversion. Model predictive control (MPC) is a simple and powerful control strategy for power electronic converters including the MC. However, weighting factor design and heavy computational burden impose significant challenges for this control strategy. This paper investigates the sequential MPC (SMPC) for a threephase direct MC. In this control strategy, each control objective has an individual cost function and these cost functions are evaluated sequentially based on priority. The complex weighting factor design process is not required and the computational burden can be reduced. In addition, specifying the priority for control objectives can be achieved. A comparative simulation study with standard MPC is carried out in Matlab/Simulink. Control performance is compared to the standard MPC and found to be comparable. Simulation results verify the effectiveness of the proposed strategy.
\end{abstract}

Keywords-Model Predictive Control (MPC); Sequential Model Predictive Control (SMPC); Matrix Converter; Weighting Factor

\section{INTRODUCTION}

The direct matrix converter (MC) carries out direct AC-to$\mathrm{AC}$ power conversion, and it does not require any bulky energy storage devices. A three-phase direct $\mathrm{MC}$ is shown in Fig. 1. This converter provides many benefits including bidirectional power flow, controllable input power factor, compact volume and higher power density [1][2]. Therefore, MCs have attracted research interest and have been investigated and proposed for several application areas. Some manufacturers such as Yaskawa and Fuji have commercialized some MC products and modules. Table I summarizes the details of some of these MC products. As seen in this table, the maximum voltage and power ratings have reached $6.6 \mathrm{kV}$ and 6 MVA, these are for the Yaskawa MX1S series. The main application area of these products is industrial motor drives.

In the literature, many control methods have been investigated for MCs. These mainly include Venturini method [3][4], space vector modulation [5][6], direct torque control [7][8], hysteresis-band control [9][10] and model predictive control (MPC) [11]-[13]. Table II summarizes the performance comparison of these common control methods. Among these controllers, MPC is regarded as a popular and promising control tool in power converters and machine drives because of its simplicity, flexibility in integrating the system constraint and potential to be applied in many areas.

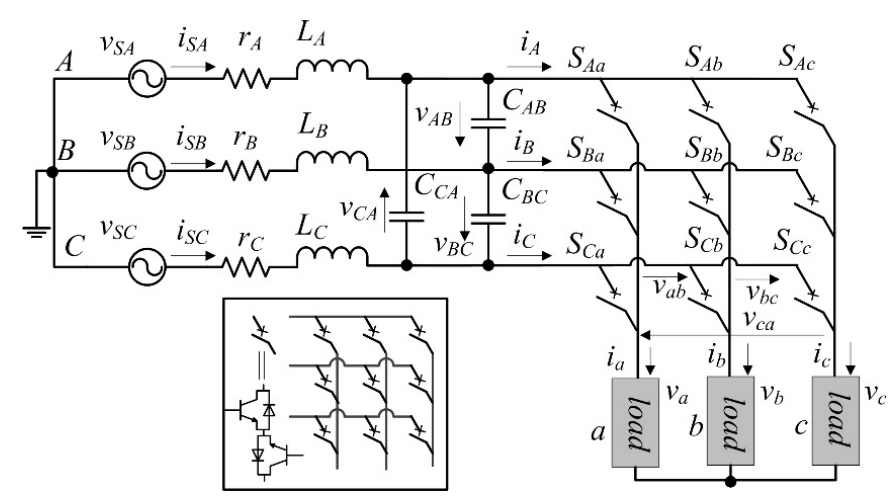

Fig. 1. Three-phase direct MC circuit.

MPC explicitly incorporates control objectives and system constraints in a cost function. All valid switch states of a converter are evaluated in this cost function to optimize the selection of switch states. The higher number of switch states results in the heavier computational burden. MPC has been investigated for most power electronic converters [14]-[17]. However, there are some drawbacks in MPC and these include complicated weighting factor design and heavy computational burden. The situation is aggravated if more control objectives need to be achieved or more switch states need to be evaluated.

The weighting factor is usually obtained using empirical methods via a trial-and-error process which is complex and time-consuming. Some research efforts have been devoted to addressing the weighting factor issues. In [18], guidelines for designing weighting factors for power converters were presented. Empirical processes are still involved in those guidelines. In [19], a multi-objective ranking-based MPC was proposed in order to regulate the torque and flux of an induction motor. Weighting factor design was avoided; however, all control objectives are treated as equal, which compromises the control. In addition, all switch states are evaluated in each cost function, resulting in heavy

This work is supported in part by the China Scholarship Council (File No. 201406300161) 
TABLE I. INFORMATION OF SOME MC PRODUCTS AND MODULES.

\begin{tabular}{cccccc}
\hline Manufacturer & Product/Model & $\begin{array}{c}\text { Max. } \\
\text { Voltage }\end{array}$ & $\begin{array}{c}\text { Max. } \\
\text { Power }\end{array}$ & Target Application & $\begin{array}{c}\text { Other } \\
\text { Information/Feature }\end{array}$ \\
\hline Yaskawa & FSDrive-MX1S & $6.6 \mathrm{kV}$ & $6 \mathrm{MVA}$ & motor drive & energy-saving \\
\hline Yaskawa & U1000 & $480 \mathrm{~V}$ & $800 \mathrm{HP}$ & motor drive & $\begin{array}{c}\text { full regeneration, ultra- } \\
\text { low harmonics }\end{array}$ \\
\hline Yaskawa & AC7 & $480 \mathrm{~V}$ & $250 \mathrm{HP}$ & motor drive & legacy product \\
\hline Yaskawa & Z1000U & $480 \mathrm{~V}$ & $350 \mathrm{HP}$ & HVAC applications & low input distortion \\
\hline Eupec & $\begin{array}{c}\text { ECONOMAC } \\
\text { FM3R12KE3ENG }\end{array}$ & $1200 \mathrm{~V}$ & $42 \mathrm{kVA}$ & unspecified & Module \\
\hline FRENIC-Mx & $400 \mathrm{~V}$ & $45 \mathrm{~kW}$ & $\begin{array}{c}\text { general industrial } \\
\text { machines }\end{array}$ & $\begin{array}{c}\text { best suitable for } \\
\text { elevators and cranes }\end{array}$ \\
\hline
\end{tabular}

TABLE II. PERFoRMANCE COMPARISON OF SOME MC CONTROL TECHNIQUES.

\begin{tabular}{cccccc}
\hline & $\begin{array}{c}\text { Venturini } \\
\text { Control }\end{array}$ & $\begin{array}{c}\text { Space Vector } \\
\text { Modulation }\end{array}$ & $\begin{array}{c}\text { Direct Torque } \\
\text { Control }\end{array}$ & $\begin{array}{c}\text { Predictive } \\
\text { Control }\end{array}$ & $\begin{array}{c}\text { Hysteresis } \\
\text { Control }\end{array}$ \\
\hline Complexity & low & high & low & very low \\
\hline Sampling Frequency & very low & low & high & high & High \\
\hline Switching Frequency & very low & low & Fast & very fast & very fast \\
\hline Dynamic Response & good & good & Nide & Narrow & very wide \\
\hline Application Range & narrow & medium
\end{tabular}

computational burden. Many other methods for avoiding weighting factors either require the conversion of the regulated variables into equivalent quantities or involve other algorithms [20]-[23]. These are undesirable because the control system complexity is increased.

This paper investigates a possible solution, i.e., the sequential MPC (SMPC), for a three-phase direct MC. In this control strategy, the complex weighting factor design process is avoided, and thus the computational burden is reduced. The contributions of this paper include: (i) an SMPC strategy is proposed and this method is investigated for a three-phase direct $\mathrm{MC}$; the regulation of different control objectives can be achieved, avoiding complex design of weighting factors; (ii) with the proposed control strategy, the cost functions corresponding to control objectives are evaluated individually and sequentially, in this way, the computational burden is reduced since only the pre-selected switch states are evaluated in the subsequent cost functions; and (iii) priority of control objectives can be specified with the proposed strategy.

A comparative simulation study is carried out to compare the performance of the proposed controller with the conventional MPC. Similar performance can be achieved, while the reduced computational burden enables further improvement of performance in the proposed strategy. Simulation results are presented to verify the proposed SMPC.

\section{PREDICTION MODELS OF MC AND LOAD}

There are nine bidirectional semiconductor switches in a three-phase direct MC, as shown in Fig. 1. These nine switches allow 27 valid switch states that need to be evaluated in the cost function of the MPC. The high number of switch states can lead to the heavy computational burden.

The semiconductor switches in an $\mathrm{MC}$ are arranged in the form of a $3 \times 3$ matrix. The relationship between the inputs and outputs of the MC can be established as

$$
\begin{aligned}
{\left[\begin{array}{c}
v_{a} \\
v_{b} \\
v_{c}
\end{array}\right]=} & {\left[\begin{array}{lll}
S_{A a} & S_{B a} & S_{C a} \\
S_{A b} & S_{B b} & S_{C b} \\
S_{A c} & S_{B c} & S_{C c}
\end{array}\right]\left[\begin{array}{l}
v_{A} \\
v_{B} \\
v_{C}
\end{array}\right]=S\left[\begin{array}{l}
v_{A} \\
v_{B} \\
v_{C}
\end{array}\right] } \\
{\left[\begin{array}{l}
i_{A} \\
i_{B} \\
i_{C}
\end{array}\right]=} & {\left[\begin{array}{lll}
S_{A a} & S_{A b} & S_{A c} \\
S_{B a} & S_{B b} & S_{B c} \\
S_{C a} & S_{C b} & S_{C c}
\end{array}\right]\left[\begin{array}{l}
i_{a} \\
i_{b} \\
i_{c}
\end{array}\right]=S^{T}\left[\begin{array}{l}
i_{a} \\
i_{b} \\
i_{c}
\end{array}\right] } \\
& \sum_{X=A, B, C} S_{X x}=1,(x=a, b, c)
\end{aligned}
$$

where $S$ (transpose $S^{\mathrm{T}}$ ) is the switch matrix and $v_{A, B, C}$ are the output phase voltages. Other variables are denoted in Fig. 1. The constraint (3) is used to exclude the invalid switch states that can cause detrimental overvoltage and overcurrent.

In MPC, system models are employed to predict the targeted variables. In order to regulate the MC output current, 
an output model needs to be developed. For an inductiveresistive load $\left(R_{a}, L_{a}\right)$, the output model can be represented as

$$
v_{a}=i_{a} R_{a}+L_{a} \frac{d i_{a}}{d t}
$$

Here the variables are defined in the Fig. 1. It is sufficient to consider a single-phase model due to the symmetry of the three-phase system. From (4), the discretized model to for output phase $a$ is obtained

$$
i_{a}[k+1]=i_{a}[k]-\frac{R_{a} T_{s}}{L_{a}} i_{a}[k]+\frac{T_{s}}{L_{a}} v_{a}[k]
$$

Here $T_{s}$ is the sampling time. The discretized model in (5) is used to predict future behavior of the load current $i_{a} . i_{a}[k]$ is measured using a current sensor and $v_{a}[k]$ is calculated using (1). Another control objective considered in this work is the input power factor. For this control objective, the input filter is modeled as

$$
v_{S A}-i_{S A} \cdot R_{A}-L_{A} \frac{d i_{S A}}{d t}=v_{A} \quad(6), \quad i_{S A}=C_{A} \frac{d v_{A}}{d t}+i_{A}
$$

Here $C_{A}$ represents the equivalent capacitance of $C_{A B}$ in star connection. From (6) and (7), the discretized input filter model can be developed in state-space as follows

$$
\begin{aligned}
& {\left[\begin{array}{l}
\dot{i}_{S A} \\
\dot{v}_{A}
\end{array}\right]=F\left[\begin{array}{l}
i_{S A} \\
v_{A}
\end{array}\right]+G\left[\begin{array}{c}
v_{S A} \\
i_{A}
\end{array}\right],} \\
& F=\left[\begin{array}{cc}
-R_{A} / L_{A} & -1 / L_{A} \\
1 / C_{A} & 0
\end{array}\right], \quad G=\left[\begin{array}{cc}
1 / L_{A} & 0 \\
0 & -1 / C_{A}
\end{array}\right] \\
& {\left[\begin{array}{c}
i_{S A}[k+1] \\
v_{A}[k+1]
\end{array}\right]=A\left[\begin{array}{l}
i_{S A}[k] \\
v_{A}[k]
\end{array}\right]+B\left[\begin{array}{c}
v_{S A}[k] \\
i_{A}[k]
\end{array}\right],} \\
& A=e^{F \cdot T_{s}}, \quad B=\int_{0}^{T_{s}} e^{F \cdot \tau} d \tau \cdot G \\
& A=\left[\begin{array}{ll}
A_{11} & A_{12} \\
A_{21} & A_{22}
\end{array}\right], A_{11}=\frac{a \cdot e^{a \cdot T_{s}}-b \cdot e^{b \cdot T_{s}}}{a-b}, \\
& A_{12}=\frac{-\left(e^{a \cdot T_{s}}-e^{b \cdot T_{s}}\right)}{L_{o a}(a-b)}, \quad A_{21}=\frac{e^{a \cdot T_{s}}-e^{b \cdot T_{s}}}{C_{a b}(a-b)}, \\
& A_{22}=\frac{a \cdot e^{a \cdot T_{s}}-b \cdot e^{b \cdot T_{s}}}{a-b}+\frac{R_{o a} \cdot\left(e^{a \cdot T_{s}}-e^{b \cdot T_{s}}\right)}{L_{o a}(a-b)} \\
& B=\left[\begin{array}{ll}
B_{11} & B_{12} \\
B_{21} & B_{22}
\end{array}\right], \quad B_{11}=\frac{e^{a \cdot T_{s}}-e^{b \cdot T_{s}}}{L_{o a}(a-b)}, \\
& B_{12}=\frac{\left[a \cdot\left(e^{b \cdot T_{s}}-1\right)-b \cdot\left(e^{a \cdot T_{s}}-1\right)\right]}{\left(L_{o a} \cdot C_{o a} \cdot a \cdot b\right) \cdot(a-b)}, \\
& B_{22}=\frac{-e^{a \cdot T_{s}}+e^{b \cdot T_{s}}+R_{o a} \cdot\left[a-b-a \cdot e^{b \cdot T_{s}}+b \cdot e^{a \cdot T_{s}}\right]}{\left(L_{o a} \cdot C_{o a} \cdot a \cdot b\right) \cdot(a-b)}
\end{aligned}
$$

with $a, b=\frac{-R_{A} / L_{A} \pm \sqrt{\left(R_{A} / L_{A}\right)^{2}-4 / C_{A} / L_{A}}}{2}$.
Therefore, the discretized model to predict $i_{S A}$ is

$$
\begin{aligned}
i_{S A}[k+1] & =A_{11} \cdot i_{S A}[k]+A_{12} \cdot v_{A}[k] \\
& +B_{11} \cdot v_{S A}[k]+B_{12} \cdot i_{A}[k]
\end{aligned}
$$

Here $i_{S A}[k], v_{S A}[k]$ and $v_{A}[k]$ are measured using sensors while $i_{A}[k]$ is calculated using (2). In order to compute the input reactive power, the three-phase variables are converted into $\alpha-\beta-\gamma$ components using

$$
\left[\begin{array}{l}
i_{\alpha} \\
i_{\beta} \\
i_{\gamma}
\end{array}\right]=\frac{2}{3}\left[\begin{array}{ccc}
1 & -1 / 2 & -1 / 2 \\
0 & \sqrt{3} / 2 & \sqrt{3} / 2 \\
1 / 2 & 1 / 2 & 1 / 2
\end{array}\right]\left[\begin{array}{c}
i_{a} \\
i_{b} \\
i_{c}
\end{array}\right]
$$

where $i_{a, b, c}$ are the three-phase currents in the $a b c$ system and $i_{\alpha, \beta, \gamma}$ are the currents in the $\alpha \beta \gamma$ system. The input reactive power is computed from

$$
Q[k+1]=\frac{3}{2}\left(\begin{array}{l}
v_{S A-\beta}[k+1] i_{S A-\alpha}[k+1] \\
-v_{S A-\alpha}[k+1] i_{S A-\beta}[k+1]
\end{array}\right)
$$

The supply voltage is considered stable and it barely changes during a short sampling cycle. Therefore $v_{S A-\alpha, \beta}[k+1]$ $=v_{S A-\alpha, \beta}[k]$ holds.

\section{SYSTEMATIC DESCRIPTIONS OF SMPC}

The system diagram of the proposed SMPC is illustrated in Fig. 2. As shown in the diagram, the proposed SMPC can be carried out in the following steps:

Step 1: Determine $n$ control objectives or variables that need to be regulated. Sort these control objectives in terms of priority (from high to low: 1st, 2nd $\cdots n$ th). Define an individual cost function $\left(g_{1}\right.$ to $\left.g_{n}\right)$ for each control objective. The cost functions will be evaluated in sequential order as explained below.

Step 2: Evaluate all $m$ available switch states (switch actions) and select $n$ most suitable switch states that render the minimum values of $g_{1}$ for regulating the first control objective.

Step 3: Evaluate the $n$ switch states selected in the previous step and select $n-1$ most suitable switch states that render the minimum values of $g_{2}$ for regulating the second control objective.

Step $x$ : Evaluate the $n-x+3$ switch states selected in the previous step and select $n-x+2$ most suitable switch states that render the minimum values of $g_{3}$ for regulating the $(x-1)$ th control objective.

Step $n+1$ : Evaluate the two switch states selected in the previous step and select the most suitable switch states that render the minimum values of $g_{n}$ for regulating the $n$th control objective.

In this work, there are two control objectives $(n=2)$, i.e., the load currents and input power factor considered in SMPC for MC. The main control objective is the regulation of the load currents, so it has the highest priority. There are $27 \mathrm{~cm}=$ 27) allowable switch states in total in the MC. The cost 


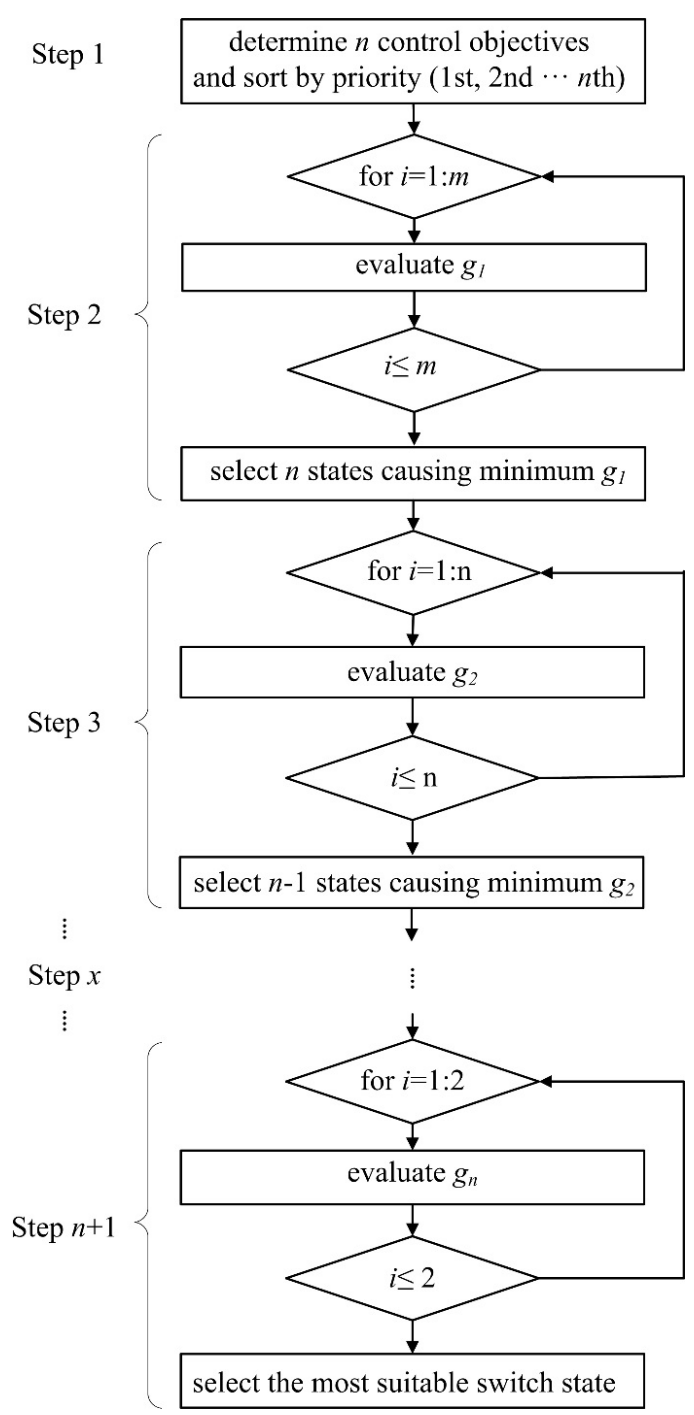

Fig. 2. System diagram of the SMPC strategy.

functions for optimizing the selection of switch states for load currents and input power factor are individually defined in

$$
\begin{gathered}
g_{1}=\left|i_{a}^{*}-i_{a}[k+1]\right|+\left|i_{b}^{*}-i_{b}[k+1]\right|+\left|i_{c}^{*}-i_{c}[k+1]\right| \\
g_{2}=\left|Q^{*}-Q[k+1]\right|
\end{gathered}
$$

Here no weighting factors need to be designed for the proposed SMPC. However, in the traditional MPC, the cost function is

$$
g=g_{1}+\lambda g_{2}
$$

where $\lambda$ is the weighting factor which is usually obtained by time-consuming empirical methods through a complex process. The weighting factor specifies the relative importance of the control objective in traditional MPC methods.

\section{Simulation Results}

In order to verify the effectiveness of the proposed controller, comparative simulation tests were carried out in Matlab/Simulink. The system and controller parameters are tabulated in Table III. The amplitude of the reference load current was set to $2 \mathrm{~A}$. The reactive power reference was set to zero because a unity power factor is desired. In the traditional MPC, a weighting factor of $\lambda=0.0008$ was used, which was obtained by a lengthy trial-and-error process. In the simulation results, the black dashed lines represent the current reference waveform (e.g., $i_{a}^{*}$ ).

Fig. 3 compares the standard MPC and the proposed SMPC in terms of the output current regulation. As observed in this figure, the performance of the proposed SMPC is very similar to the standard MPC. The total harmonic distortion (THD) in the standard MPC is $4.07 \%$ while it is $3.95 \%$ in the proposed SMPC. Fig. 4 compares the input power factor regulation of two methods. Both methods can regulate the input current to be in phase with the input voltage, resulting in unity power factor. As concluded from these results, the proposed SMPC exhibits comparable results to the standard MPC. However, the complex weighting factor design is not required in the proposed SMPC.

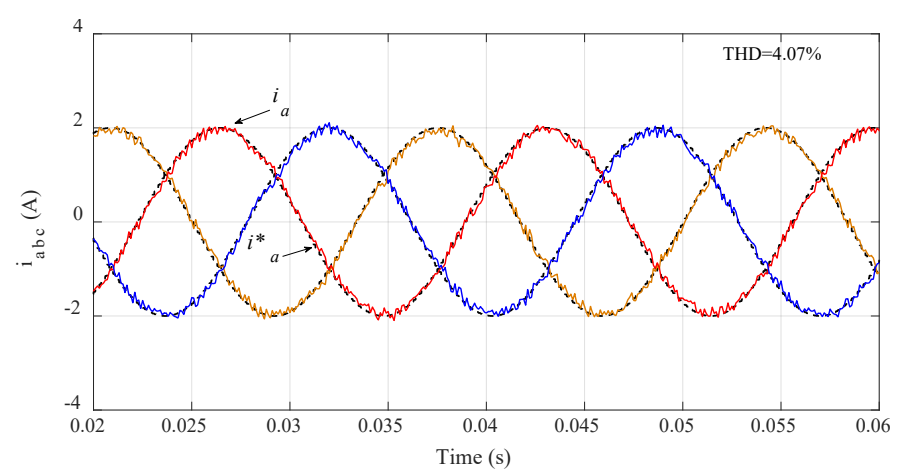

(a)

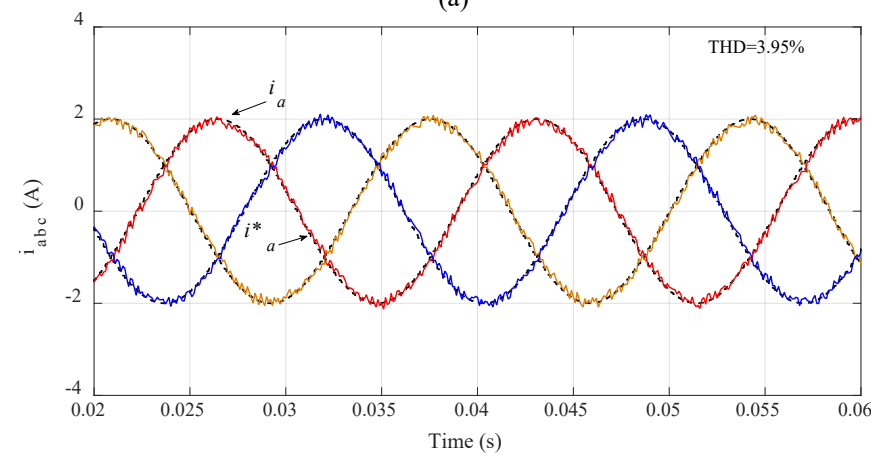

(b)

Fig. 3. Simulation results of controlled load currents by (a) MPC, and (b) proposed SMPC. 


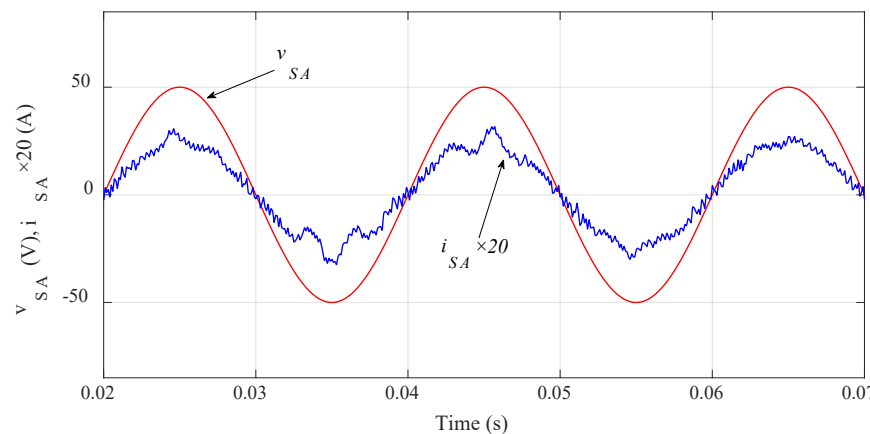

(a)

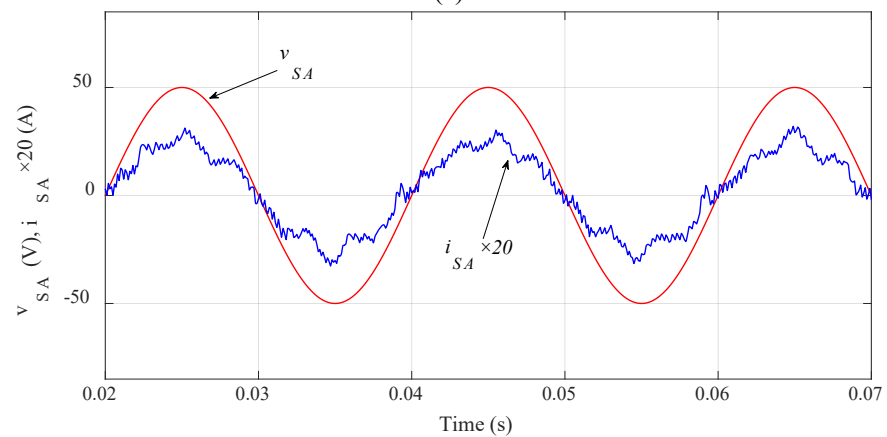

(b)

Fig. 4. Simulation results of controlled input power factor by (a) MPC, and (b) proposed SMPC.

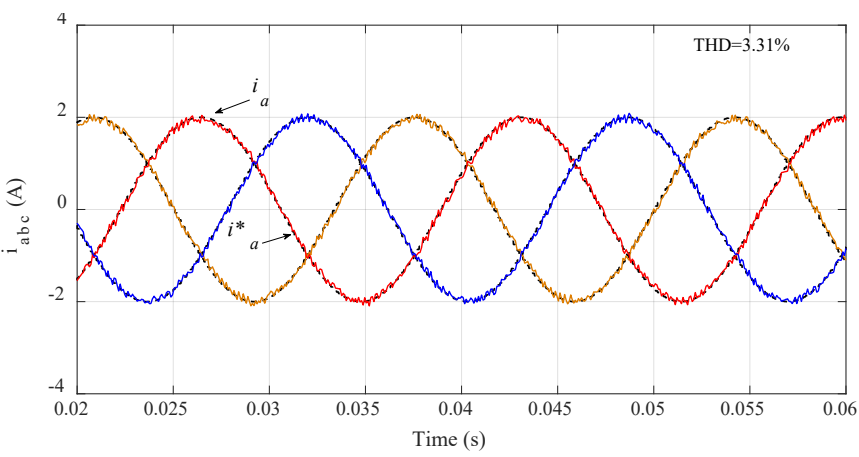

(a)

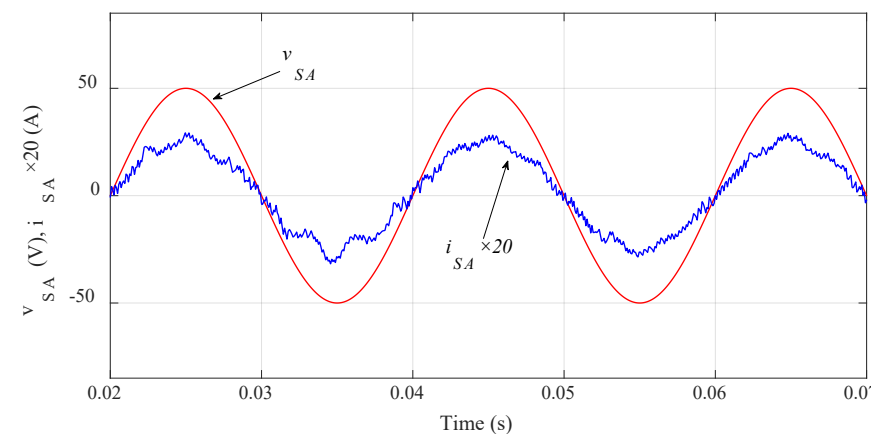

(b)

Fig. 5. Simulation results of (a) controlled currents, and (b) input power factor by the proposed SMPC when $T_{s}=80 \mu \mathrm{s}$.

The proposed SMPC reduces the computational burden and can potentially further improve the performance. Compared with the standard MPC, the computation burden is reduced because only the pre-selected switch states are evaluated in the second and subsequent sequential cost functions. In addition, the prediction model computation for the following cost functions is also reduced. These further improve the performance by increasing the sampling frequency of the algorithm. However, this is difficult to achieve in the standard MPC because all switch states are evaluated in all cost functions; otherwise some pre-selection technique has to be applied. In order to verify this benefit of the proposed SMPC, the sampling time was reduced to $80 \mu \mathrm{s}$, which should comply with the future experimental implementation. The simulation results for the proposed SMPC with $T_{s}=80 \mu \mathrm{s}$ are shown in Fig. 5. The regulated output current is improved in terms of the waveform and THD $(3.31 \%)$ and the input waveform is also improved.

Table IV compares and summarizes the performance of SMPC and MPC. The proposed SMPC performs similarly to the standard MPC in terms of the evaluated performance with a slightly lower average switching frequency. These simulation results demonstrate the effectiveness of the proposed SMPC.

TABLE III. SYSTEM AND CONTROLLER PARAMETERS

\begin{tabular}{rrrrrrrrrr}
\hline$v_{s}\left[\mathrm{~V}_{\mathrm{pk}-\mathrm{pk}}\right]$ & $f_{s}[\mathrm{~Hz}]$ & $L_{A}[\mathrm{mH}]$ & $C_{A}[\mu \mathrm{F}]$ & $R_{A}[\Omega]$ & $R_{L}[\Omega]$ & $L_{L}[\mathrm{mH}]$ & $f_{o}[\mathrm{~Hz}]$ & $Q^{*}[\mathrm{VAr}]$ & $T_{s}[\mu \mathrm{s}]$ \\
\hline 100 & 50 & 6.8 & 10 & 0.5 & 15 & 14 & 60 & 0 & 100 \\
\hline
\end{tabular}

TABLE IV. COMPARATIVE PERFORMANCE EVALUATION OF SMPC AND MPC.

\begin{tabular}{cccccc}
\hline & $T_{s}$ & $\begin{array}{c}\text { Avg. Switching } \\
\text { Frequency }\end{array}$ & Weighting Factor & $\begin{array}{c}\text { Output Current } \\
\text { THD }\end{array}$ & $\begin{array}{c}\text { Input Power } \\
\text { Factor }\end{array}$ \\
\hline MPC & $100 \mu \mathrm{s}$ & $2.038 \mathrm{kHz}$ & 0.0008 & $4.07 \%$ & 0.997 \\
\hline $\mathrm{SMPC1}$ & $100 \mu \mathrm{s}$ & $1.89 \mathrm{kHz}$ & none & $3.95 \%$ & 0.996 \\
\hline $\mathrm{SMPC2}$ & $80 \mu \mathrm{s}$ & $2.37 \mathrm{kHz}$ & none & $3.31 \%$ & 0.997 \\
\hline
\end{tabular}




\section{CONCLUSIONS}

An SMPC is proposed for a three-phase direct MC in this paper. In the proposed SMPC strategy, each control objective has an individual cost function. These cost functions are evaluated in sequential order according to the pre-determined priority. Weighting factor design is avoided in the proposed strategy, so the controller design process is simplified. In addition, the computational burden is reduced because only the pre-determined switch states are evaluated in the subsequent cost functions. The computation of prediction models for the following cost functions is reduced as well. These enable further enhancement of the control performance by increasing the sampling frequency. The comparative results to the standard MPC are achieved. The effectiveness of the proposed controller is verified by the simulation results. The proposed controller becomes more beneficial when more control objectives and more switch states are considered. The proposed SMPC can be readily extended to other converters and systems. The experimental work will be carried out to support the simulation results and verify the effectiveness of the proposed SMPC.

\section{REFERENCES}

[1] P. Wheeler, J. Rodriguez, J. C. Clare, L. Empringham, and A. Weinstein, "Matrix converters: A technology review," IEEE Trans. Ind. Electron., vol. 49, no. 2, pp. 276-288, 2002.

[2] A. Trentin, L. Empringham, L. Lillo, P. Zanchetta, P. Wheeler, and J. Clare, "Experimental Efficiency Comparison Between a Direct Matrix Converter and an Indirect Matrix Converter Using Both Si IGBTs and SiC mosfets," IEEE Trans. Ind. Appl., vol. 52, no. 5, pp. 4135-4145, 2016.

[3] M. Venturini, "A new sine wave in sine wave out, conversion technique which eliminates reactive elements," in Proc. Powercon 7, 1980, pp. E3/1-E3/15.

[4] J. Rodriguez, E. Silva, F. Blaabjerg, P. Wheeler, J. Clare, and J. Pontt, "Matrix converter controlled with the direct transfer function approach: Analysis, modelling and simulation," Int. J. Electron., vol. 92, no. 2,pp. 63-85, Feb. 2005.

[5] L. Huber, D. Borojevic, "Space vector modulated three-phase to threephase matrix converter with input power factor correction," IEEE Trans. Ind. Appl., no. 6, pp. 1234-1246, 1995.

[6] J. Zhang, D. G. Dorrell, L. Li, Y. Guo, "Decoupling Controller Design and Controllable Regions Analysis for the Space Vector Modulated Matrix Converter-Unified Power Flow Controller in Transmission Systems," Electric Power Components Systems, vol. 46, no. 1, pp. 1-14, 2018.

[7] Casadei, D., Serra, G., Tani, A.: 'The use of matrix converters in direct torque control of induction machines,' IEEE Trans. Ind. Electron., 2001, 48, (6), pp. 1057-1064.

[8] C. Ortega, A. Arias, C. Caruana, J. Balcells, and G. Asher, "Improved waveform quality in the direct torque control of matrix-converter-fed PMSM drives," IEEE Trans. Ind. Electron., vol. 57, no. 6, pp. 21012110, Jun. 2010.

[9] J. Zhang, L. Li, L. Zhang, D. G. Dorrell, "Hysteresis Band Current Controller based Field-Oriented Control for an Induction Motor driven by a Direct Matrix Converter," 43rd Ann. Conf. IEEE Ind. Electron. Society (IECON 2017), Beijing, China, pp. 4633-4638, November 2017.

[10] J. Zhang, H. Yang, T. Wang, L. Li, D. G. Dorrell, D.D.C. Lu, "FieldOriented Control based on Hysteresis Band Current Controller for a Permanent Magnet Synchronous Motor driven by a Direct Matrix Converter," IET Power Electronics, DOI: 10.1049/iet-pel.2017.0651, 2018.

[11] M. Rivera, C. Rojas, J. Rodriguez, P. Wheeler, B. Wu, and J. R. Espinoza, "Predictive current control with input filter resonance mitigation for a direct matrix converter," IEEE Trans. Power Electron., no. 99, 2011.

[12] L. Wang, H. Dan, Y. Zhao, Q. Zhu, T. Peng, Y. Sun, and P. Wheeler, "A finite control set model predictive control method for matrix converter with zero common-mode voltage," IEEE J. Emerging and Selected Topics in Power Electron., vol. 6, no. 1, pp. 327-338, 2018.

[13] J. Zhang, L. Li, Z. Malekjamshidi, and D. G. Dorrell, "Predictive Voltage Control of Direct Matrix Converter with Reduced Number of Sensors for the Renewable Energy and Microgrid Applications," IEEE Energy Conversion Congress Expo. (ECCE), Cincinnati, USA, pp. 3309-3315, Oct. 2017.

[14] S. Vazquez, J. I. Leon, L. G. Franquelo, J. Rodriguez, H. A. Young, A. Marquez, and P. Zanchetta, "Model predictive control: A review of its applications in power electronics," IEEE Ind. Electron. Magazine, vol. 8, no. 1, pp. 16-31, 2014.

[15] S. Vazquez, J. Rodriguez, M. Rivera, L. G. Franquelo, and M. Norambuena, "Model predictive control for power converters and drives: Advances and trends," IEEE Trans. Ind. Electron., vol. 64, no. 2, pp. 935-947, 2017.

[16] J. Rodriguez, M. P. Kazmierkowski, J. R. Espinoza, P. Zanchetta, H. Abu-Rub, H. A. Young, and C. A. Rojas, "State of the art of finite control set model predictive control in power electronics," IEEE Trans. Ind. Informatics, vol. 9, no. 2, pp. 1003-1016, 2013.

[17] M. Norambuena, J. Rodriguez, Z. Zhang, F. Wang, C. Garcia, and R. Kennel, "A Very Simple Strategy for High Quality Performance of AC Machines Using Model Predictive Control," IEEE Trans. Power Electron., DOI: 10.1109/TPEL.2018.2812833, 2018

[18] P. Cortés, S. Kouro, B. La Rocca, R. Vargas, J. Rodríguez, J. I. León, S. Vazquez, and L. G. Franquelo, "Guidelines for weighting factors design in model predictive control of power converters and drives," IEEE Int. Conf. on Ind. Tech., pp. 1-7, 2009.

[19] C. A. Rojas, J. Rodriguez, F. Villarroel, J. R. Espinoza, C. A. Silva, and M. Trincado, "Predictive torque and flux control without weighting factors," IEEE. Trans. Ind. Electron., vol. 60, no. 2, pp. 681-690, 2013.

[20] J. Zhang, L. Li, D. G. Dorrell, J. Rodriguez, M. Norambuena, "Investigation of Grid-Connected and Islanded Direct Matrix Converter for the Renewable Microgrid Applications with Model Predictive Control," 2018 IEEE Energy Conversion Congress and Exposition (ECCE 2018), Oregon, U.S., 2018.

[21] Y. Zhang, and H. Yang, "Two-vector-based model predictive torque control without weighting factors for induction motor drives," IEEE Trans. Power Electron., vol. 31, no. 2, pp. 1381-1390, 2016.

[22] P. Zanchetta, "Heuristic multi-objective optimization for cost function weights selection in finite states model predictive control," IEEE Workshop Predictive Control Electr. Drives Power Electron. (PRECEDE), pp. 70-75, 2011.

[23] S. Davari, D. A. Khaburi, and R. Kennel, "An improved FCS-MPC algorithm for an induction motor with an imposed optimized weighting factor," IEEE Trans. Power Electron., vol. 27, no. 3, pp. 1540-1551, 2012. 